\title{
Analysing the potential of plant clinics to boost crop protection in Rwanda through adoption of IPM: the case of maize and maize stem borers
}

\author{
Silvia Silvestri ${ }^{1}$ (D) Martin Macharia ${ }^{1,2} \cdot$ Bellancile Uzayisenga $^{3}$
}

Received: 1 June 2018 / Accepted: 5 March 2019 /Published online: 25 March 2019

(C) The Author(s) 2019

\begin{abstract}
Maize plays an important role in the livelihoods of rural communities in Rwanda. However, maize yields are threatened by the presence of pests and diseases and a general lack of knowledge and information for their management. In this study we sought to assess if plant clinics are making farmers more aware and knowledgeable of pests and diseases and are indirectly contributing to higher yields. We interviewed 644 farmers across Rwanda, both users and non-users of plant clinics. Propensity score matching was used to match the users and non-users of plant clinics and logistic regression was used to assess a number of factors, including interactions with plant clinics, that affect farmers' adoption of pest management practices. Our analysis shows that users of plant clinics are more aware and knowledgeable in recognizing and handling maize stem borers. Furthermore, users of plant clinics have on average higher yields than non-users and this difference is highly significant $(P<0.001)$. The analysis therefore demonstrates that plant clinics are beneficial to farmers in Rwanda. However, efforts are required to diversify the spectrum of practices that are promoted by plant clinics and by extension and advisory services in Rwanda.
\end{abstract}

Keywords Plant clinics $\cdot$ Maize $\cdot$ Pests $\cdot$ Awareness $\cdot$ Adoption $\cdot$ Productivity $\cdot$ Gender

\section{Introduction}

Crop pests and diseases are common and important threats to the livelihoods of farmers in sub-Saharan Africa (Geddes 1990; Rweyemamu et al. 2006), where farmers live mainly on subsistence agriculture (Thornton et al. 2008, 2010). In Rwanda over $90 \%$ of the population live in rural areas and survive on subsistence agriculture: therefore, any crop loss, including those caused by pests and diseases, can have devastating effects on their livelihoods.

Silvia Silvestri

s.silvestri@cabi.org

Martin Macharia

machariamartin4@gmail.com

Bellancile Uzayisenga

bellancile@gmail.com

CAB International, P.O. Box 633-00621, Nairobi, Kenya

2 The Greenlight Planet, Argwings Kodhek Rd, Nairobi, Kenya

3 Rwanda Agriculture Board (RAB), KG 569 Street, Kigali, Rwanda
Farmers need to be provided with options to address pest and disease outbreaks that are context-specific to their agricultural conditions and socioeconomic circumstances (Danielsen et al. 2013). Extension and advisory services can play important roles in supporting farmers to address the threats of pests and diseases and therefore enhancing productivity and food security. Conventional extension approaches often fail to reach and address the diverse needs of resource-poor farmers (Danielsen and Matsiko 2016). This is mainly because these approaches tend to be biased towards specific crops and areas and are not flexible enough to support farmers who have to cope with the unpredictable changes and emerging challenges faced by the wide range of crops they grow (Danielsen and Matsiko 2016).

The idea of plant clinics was developed in the early 2000s by the Global Plant Clinic Alliance. The approach promoted by plant clinics was first started in Bolivia in 2003 (Bentley et al. 2007, 2009; Boa 2010; Danielsen and Kelly 2010) and later expanded to other countries, at different rates and in different ways. Plant clinics in Rwanda were first piloted in 2011 (Majuga et al. 2018).

Plant clinics, a relatively new extension method, try to respond to farmers' demands for technical advice to solve plant health problems (Danielsen et al. 2013; Boa et al. 2016). 
They are managed by extension agents, called plant doctors, and are usually organized in proximity to farmer-friendly public spaces, such as markets. Plant doctors give advice and recommendations to farmers based on field diagnosis and available information. They face the challenge of having to address multiple crops and plant health problems that farmers present. Plant doctors often make several recommendations for a single problem, which is consistent with integrated pest management (IPM) (Ehler 2006; Bentley et al. 2018).

Because plant clinics vary in how they operate and the services they offer (Boa et al. 2016), a brief description of them in Rwanda is provided below.

Plant clinics are run by plant doctors from Local Government and the Rwandan Agricultural Board (RAB) (Majuga et al. 2018). Every plant clinic operates at a market place twice a month. The responsibilities of plant clinics in Rwanda include: i) identification of the causes of plant health problems and prescription of management options; ii) field visits and inspection of pest and disease problems, advice and guidance to farmers for the management of plant health problems.

In Rwanda (between November 2015 and November 2016) there were 61 plant clinics that received in total 870 queries from farmers related to beans, Irish potatoes and maize. About 470 queries were related to maize.

The expectation of the plant clinic approach is that farmers and their households will benefit in terms of changes in knowledge and management of pests and diseases, and improved livelihoods. Assessing farm level impact of plant clinics requires a variety of methods, approaches and designs to assess changes, direct and indirect, expected and unexpected, that contribute to farm-level and other improvements. Studies have been conducted to establish outcomes for plant clinics in Bolivia (Bentley et al. 2009), Bangladesh (Rajendran and Islam 2017), Uganda (Brubaker et al. 2013), Kenya (AIR 2015) and Rwanda (Nsabimana et al. 2015). The majority of these studies showcase increased harvest for plant clinic users and behavioural change among farmers.

Yet, in countries such as India and the USA where plant clinics were established long ago, limited information is available on the evaluation of plant clinics on increasing food productivity. Therefore, a more formal and comprehensive quantifying of plant clinics would be beneficial to establishing the extent to which this extension service leads to changes in knowledge and practices for pest and disease management and ultimately to food security and livelihood improvement (Srivastava 2013).

This study sought to assess the impact of plant clinics in improving farmers' knowledge and adoption of integrated pest management practices (IPM) in Rwanda, in particular for maize stalk borer (MSB), Busseola fusca (Fuller). In doing so, the study examines the extent to which plant clinics are making farmers more knowledgeable of pests and diseases, and are promoting adoption of integrated pest management (IPM) practices, that favour higher maize yield.

It is hoped that the results from this study will provide an incentive for promotion and out-scaling of plant clinics as a model of extension for other countries.

\section{Analytical methods}

\subsection{Sampling strategy and survey implementation}

A quasi-experimental approach was used for this study. This approach allowed controlling for selection bias as farmers were not randomly assigned to treatment (where by 'treatment' we mean farmers visiting and therefore using plant clinics) and control (where by 'control' we mean farmers not visiting and therefore not using plant clinics). Furthermore, because of costs constraint, it was not feasible to implement randomized control trials (RCT), as previously done in other studies (AIR 2015).

Plant clinic data were obtained from the Plantwise Knowledge Bank, which is a repository for plant health information. The data were analysed for the prevalence of crops and problems presented and the types of recommendations given. This indicated that maize was the most frequent crop brought to plant clinics. The distribution of the farmers that attended the plant clinics and brought maize damaged by stalk borer guided site selection. At the time when the survey was implemented there were no queries recorded on fall armyworm, Spodoptera frugiperda (Smith) at the plant clinics or, more broadly, at the national level in Rwanda. Maize and maize stalk borer (MSB) were chosen because of the occurrences in the study, and because maize is a priority staple crop in Rwanda (Wanda et al. 2002; Macauley and Ramadjita 2015).

Data for this study were collected from 13 districts and 14 sectors spanning 4 agro-ecological zones (AEZ): Cone and High Volcanic Plains, Buberuka Highlands, Congo Nile Watershed Divide and Central Plateau. Study sites were selected across four different AEZs of Rwanda. A summary of the characteristics of the AEZs and the number of farmers interviewed after propensity score matching (PSM) (Rosenbaum and Rubin 1983) is presented in Table 1.

A sample of 644 farmers was interviewed, out of which 260 were users of plant clinics (hereafter 'users') and 384 were non-users of plant clinics (hereafter non-users').

The variables used to select clinic users sites were also used to select non-user sites. The control group was as similar as possible to the treatment group in terms of socio-economic (pre-intervention) characteristics. Characteristics considered were: i) similarity of agro-ecological zone, a necessary condition because elements such as soil, temperature and rainfall are important drivers of production; ii) similarity of crops 
Table 1 AEZs where the survey took place and number of household per AEZ

Agro-ecological zone

Number of $\mathrm{HHs}^{\mathrm{a}}$

\begin{tabular}{l} 
Users \\
\hline The Cone and High Volcanic Plain \\
The average altitude is $2200 \mathrm{~m}$, and the average rainfall is about $1500 \mathrm{~mm}$. Average temperature is $17{ }^{\circ} \mathrm{C}$. The main \\
crops are potatoes, wheat, peas, maize, common beans. \\
Buberuka Highlands \\
The average altitude is $2000 \mathrm{~m}$, and the average rainfall is about $1200 \mathrm{~mm}$. Average temperature is $16{ }^{\circ} \mathrm{C}$. The main \\
crops are potatoes, maize, common beans, wheat and peas. The main cash crop is tea. \\
Congo Nile Watershed Divide \\
The altitude varies between 1900 and 2200 m. Annual rainfall ranges between 1400 and 1500 mm. The minimum \\
temperature is $14{ }^{\circ} \mathrm{C}$ and the maximum temperature is $30{ }^{\circ} \mathrm{C}$. The main crops are common beans, maize, sweet \\
potatoes, sorghum and peas. Common cash crops are tea, banana and coffee. \\
Central Plateau \\
The altitude characterizing this zone ranges between 1500 and 2100 m, annual rainfall between 1000 and 1600 mm \\
that increases with altitude. The average temperature is about $19{ }^{\circ} \mathrm{C}$ with minimum of $10{ }^{\circ} \mathrm{C}$ and maximum of \\
$30{ }^{\circ} \mathrm{C}$. \\
Mixed cropping and rotation practices are well known practices in the area. The important crops are cassava, sweet \\
potato, banana, bean, sorghum, maize. Coffee is the main cash crop. \\
TOTAL \\
\hline
\end{tabular}

${ }^{a}$ This only includes households that were kept in the analysis after PSM

grown; iii) similarity of pests and diseases; iv) absence of spill-over effect into the non-clinic user area.

The proportion between users and non-users was approximately 1:1.5 with more control respondents to ensure that a matched group could be created. From a gender perspective, 351 interviews were conducted with male farmers and 293 with female farmers.

The household survey was conducted in May 2017, in line with the cropping season and included information about: household size and composition; household assets; maize yield; agricultural inputs (use and barriers to use) and labour use for cropping; interventions for pest management; sources of information for pests and diseases; market; reasons for crop failure; access to credit. Farmers were asked also about practices dismissed and introduced during the last two cropping seasons before survey implementation. Data collection was done by trained local enumerators, through face to face interviews conducted using tablets with the questionnaire inbuilt using Open Data Kit (ODK) technology (Hartung et al. 2010).

\subsection{Data analysis}

Propensity score matching (PSM) technique was applied to enable a valid comparison group and reduce the risk of bias. PSM is a statistical matching technique that enables selection of users and non-users of plant clinics with similar characteristics. In this study, PSM allowed comparison of users and non-users with respect to the use of IPM and yields of maize. PSM reduces the possibility that the observed differences in the outcomes between the two groups of interest may be due to an imperfect match rather than caused by the intervention
(Adelson 2013; Rudner and Peyton 2006; Stone and Tang 2013).

PSM was done in R (R Core Team 2016) using the MatchIt package (Ho et al. 2011) with nearest-neighbour 1-to-1 matching and a calliper of 0.16 . In its simplest form, 1:1 nearest neighbor matching selects for each treated individual $i$ the control individual with the smallest distance from individual $i$ (Stuart 2010). A calliper is the maximum tolerated standard deviation between matched subjects. Several matching methods were fitted but the nearest neighbour technique was found to be the best, giving standardized mean difference of variables much below 0.1 .

The following set of variables was used in the PSM and model fitting: importance of on-farming activities for the household; total household members; household members above 15 years (this is a proxy for household labour supply, considering the threshold of 15 as the minimal working age, ILO 2004); gender of the respondent; age of the respondent; level of education of the respondent; total land cultivated with maize; young dependent ratio (given by the ratio of dependents aged 14 years and below to total household size).

This yielded a final number of 430 households considered in the analysis, out of which 215 were users (of plant clinics) and 215 were non-users (of plant clinics).

Data analysis was conducted using both descriptive and inferential statistics. Data were analysed using the R statistical package. Inferential statistics were used such as t-test, nonparametric (chi-squared) test, Wilcoxon rank sum test with continuity correction, and logistic regression. This helped ascertain the level of significance of difference for selected parameters, between users and non-users and across gender categories. 


\subsection{Indicators of impact}

The primary objective of any extension approach is to influence farmer learning in such a way that it influences positive change in farming practices and application of technologies. We evaluated the efficacy of the extension service provided by plant clinics through the application of the awareness, knowledge, adoption, productivity (AKAP) sequence (Evenson 1996).

Awareness and knowledge In this study awareness and knowledge are bundled and are measured in terms of capacity of farmers to recognize symptoms of MSB presence. Farmers were shown 12 pictures of maize plants affected by MSB and were asked whether they thought these pictures indicated the presence of a pest in the maize plant. Awareness of the presence of a problem, is a necessary, although not sufficient, prerequisite for adoption, together with the knowledge of alternatives, the motivation for change and the resources to implement change (Hatfield and Karlen 1994).

Adoption Adoption was measured by how many suitable practices for pest management the farmers implemented. An implicit hypothesis is that users of plant clinics have access to a greater array of information about interventions options than the non-users of plant clinics; in turn this would, on average, lead to a greater amount of pest management practices in place.

Productivity Productivity was measured in terms of yield of maize per hectare (ha). An implicit hypothesis is that users of plant clinics would on average have a greater knowledge of the practices to implement. This would help them to prevent/ contain the impact of MSB in their maize fields and therefore preserve yields.

\subsection{Analysis of determinants of adoption}

A logistic regression was used to analyse the factors influencing farmers' adoption of pest management practices for MSB. This allowed analysis of what set of determinants could influence adoption, besides plant clinics. The data analysis followed four steps:

\subsubsection{Definition of categories for pest management practices}

The first step was the aggregation of pest management practices for MSB into eight main categories. Practices were aggregated according to their purpose. Table 2 shows the categories, the corresponding pest management practices and explains the selection of the categories.

The adoption of each of the categories of technique was measured as a binary variable, with 1 meaning that at least one practice within each category was adopted and 0 meaning that none of the practices within a specific category was adopted.

\subsubsection{Selection of adoption determinants}

The second step was to select drivers of adoption for the eight categories of pest management practices. These determinants of adoption were later tested for heterogeneity and multicollinearity for inclusion in the model. The selected variables were classified into three main categories namely:

a) social and environmental characteristics, including: gender and age of the respondent; household size; level of education; labour surplus, deficiency and balance; shocks.

b) economic factors, including: area under maize cultivation; maize yields; net income; costs of inputs; access to credit and other sources of cash; household asset index; inputs received for free.

c) information sources, including only those sources that were used by at least 5 farmers. Information sources were chosen among the following ones: own experience; another household member; neighbours; friends and family; agricultural programmes on the TV; government extension officers; books/flyers/pamphlets; agro-dealers; demonstration plots/field days; farmers promoters; RAB agronomist; NGO; agricultural shows; newspapers/ magazines /bulletins; mobile sms and voice services; farmers field school (FFS)/farmers facilitators; plant clinics/plant doctors; women's group.

Labour surplus, deficiency and balance provide an indication of labour availability at household level. This was computed as the ratio of the total land farmed by a household to the number of household members. In determining the number of household members to supply labour, those above the age of 15 were considered. It is assumed that one individual above this age is capable of cultivating 1 ha of land in a season (LNV and Euroconsult 1989). A ratio equal to 1 indicated labour balance: farm labour is enough for the cultivated land. A ratio lower than 1 indicated a labour shortage and a ratio greater than 1 indicated a labour surplus at the household level.

Shocks were defined by different phenomena that can cause crop failure: pests and diseases, excess rain or flooding, drought or insufficient water, hailstorms, crop destroyed by livestock, theft, and sickness of the farmer.

The household asset index was calculated with the simple poverty scorecard that uses low-cost indicators from Rwanda's 2010/11 Integrated Household Living Standards Survey to estimate the likelihood that a household has consumption below a given poverty line (Schreiner 2016). 
Table 2 Set of eight pest management practices for Maize Stork Borer Control

\begin{tabular}{lcc}
\hline Categories & Pest management practices for MSB & Explanation of the selection of the categories \\
\hline $\begin{array}{l}\text { Cultural } \\
\text { prevention/avoidance }\end{array}$ & $\begin{array}{c}\text { Early planting (plant early so the plant is well established when } \\
\text { the pest comes, and it has more chance of surviving) } \\
\text { - Frequent weeding (to remove alternative host plants) } \\
\text { - Improve soil fertility - manure or chemical fertilizer (to stimulate } \\
\text { strong plant growth and ability to tolerate pest attack) }\end{array}$ & $\begin{array}{c}\text { This category includes the first line of defence } \\
\text { that might be put in place by farmers to } \\
\text { prevent a pest population from infesting a } \\
\text { crop or field, together with some cultural } \\
\text { practices that can be put in place to avoid the } \\
\text { impact of the pest }\end{array}$ \\
$\begin{array}{l}\text { Cultural } \\
\text { planting/cropping } \\
\text { patterns }\end{array}$ & $\begin{array}{l}\text { Intercrop maize with non-host non legume crops such as cassava } \\
\text { These include cultural practices associated with } \\
\text { implementation of specific planting and } \\
\text { cropping patterns }\end{array}$
\end{tabular}

- Trap cropping: use a trap plant e.g. Napier grass-Urubingo as a border crop (to draw/'pull' pest out of maize crop and into this preferential host plant)

- Push-pull: use a trap plant e.g. Napier grass-Urubingo as a border crop (to draw/'pull' pest out of maize crop and into this preferential host plant) and intercrop with a repellent plant e.g. legume such as Desmodium (to 'push' repel pest out of the crop area) (these options work also alone but are more effective together)

- Crop rotation - recommended to rotate with non-host plants e.g. legumes, cotton, sunflower, etc. (to avoid build up of pests)

Cultural resistance/Tolerant varieties

Mechanical late stage interventions

Mechanical early stage intervention

Biological control

Pesticide

Monitoring
- Plant resistant varieties/tolerant varieties

- Uproot and burning of infected plants (to destroy larvae and pupae)

- Plough infected stalks deep into soil (deeper than $30 \mathrm{~cm}$ to kill larvae \& prevent adult emergence) - bury them. The larvae will not survive and if they pupate (begin to change into adults) then the adult insects will not survive.

- Feeding stubble to livestock (to destroy larvae and pupae)

- Remove crop residues that are damaged by pests or diseases (to remove pest from the field and avoid build up in following year)

- Handpicking young larvae (needs labour and only effective for early larval stages before larvae enter the stem)

- Early slashing of maize stubble and laying it out on the ground (exposes the pest larvae or pupae to sun (heat $\&$ drying) and/or to predators such as ants/birds) - cut it down and make it lie on the ground to capture sun that can kill any larvae

- Applications of dusts to the leaf e.g. apply fine wood ash (dust) to leaves affected by larvae (before they enter the stem). Ash dust can be mixed with a pinch of dry chilli (Insecticide and irritant)

- Application of Neem powder - can be mixed (1:1) with dry clay or sawdust - wood dust (natural insecticide and irritants)

- Biological control options - Encouraging natural enemies (predators \& parasites) into field by planting their host plants in field boundaries - the plants are the ones that host the predators and parasites. Larvae can be eaten by birds, spiders, ants and killed by parasitic wasps; wasps lays their eggs inside the larvae and when they grow they kill the larvae.

- Application of Pesticides - several different options are available as granules, dusts or sprays

- Monitoring the stem borer (checking for insects) - when the larvae are very young using ash can be effective in killing the pest. Once the larvae are older it is too late for this intervention.
These resist or tolerate MSB, reducing loss to the pest

These include suppressive type of practices that are implemented on the crops and fields at a late stage of development of the pest, when the damage by the pest has already caused economic losses

These include suppressive type of practices that are implemented on the crops and fields at an early stage of development of the pest, to avoid economic losses

These involve the use of other organisms to suppress MSB

This includes a suppressive type of practice based on use of chemical pesticide

This includes prevention practices that allow checking for presence of the pest on the crops and field. 


\subsubsection{Assessing the influence of the three categories of determinants on adoption}

The influence of the determinants of adoption on the uptake of pest management practices was assessed through a fitted logistic regression. The dependent variables were dummy variables taking the value of 1 if farmer $i$ adopted a determined practice and 0 otherwise. A farmer $i$ chooses a certain adaptation measure if the derived benefits $B_{i}$ are higher than a certain threshold $T$ (Kabubo-Mariara 2008; Staal et al. 2002):

$Y_{i}=1$ if $B_{i}>\mathrm{AM} \rightarrow X_{i} \beta+\alpha_{i}>\mathrm{AM}$ farmer i decides to adopt

$Y_{i}=0$ if $B_{i}<\mathrm{AM} \rightarrow \mathrm{X}_{\mathrm{i}} \beta+\alpha_{\mathrm{i}}<\mathrm{AM}$ farmer i decides not to adopt

Where $X_{i}$ is a vector of explanatory variables, $\beta$ is a vector of coefficients to be estimated and $\alpha_{i}$ is an independent, farm specific, ex ante stock. The model has the form:

$Y_{i}=x_{i} \beta+\alpha_{i}$

Where $x_{i}$ is a vector of explanatory variables derived from the survey, $\beta$ is the corresponding regression coefficients and $\alpha_{i}$ are the intercept parameters.

\subsubsection{Evaluating potential for adoption of agricultural practices}

The last step was to evaluate the potential for adoption of the eight pest management practices for MSB. The likelihood of adoption was derived from the coefficients of the categories, estimated through the logistic model. The probability of adoption of each category of pest management practices was calculated by substituting the $\beta$ in Eq. (1) by the estimated coefficients in the logistic regressions.

\section{Results and discussion}

\subsection{Sources of information}

Farmers in Rwanda access information on pests and diseases from a variety of sources: through personal experience; consultation with peers; plant doctors and other extension officers from the government; and various other sources of information as illustrated in Fig. 1. The most frequent responses were reliance on personal experience and on information sources based on personal relationships, which might include other household members, neighbours, and friends and family, but also reliance on local experts such as trained farmer facilitators, extension officers, agro-dealers, farmers field schools (FFS), RAB agronomists, and plant doctors where available, to mention some.

There are a few information sources that seem to be the prerogative of male farmers and are not used at all by female farmers, such as participation in agricultural shows and use of reading material (such as books, flyers and pamphlets), though both these seem to be rare in any case. Mainly female respondents sought help from household members. There are other sources of information whose access significantly differs between male and female farmers. These include sources such as farmer promoters, NGOs and RAB agronomists who seem to be mainly targeting male rather than female farmers. These results confirm that male farmers have access to a more diversified set of information and, as found in literature, are in general the target of information from these dissemination sources (Kristjanson et al. 2017; Perez et al. 2014; Bryan et al. 2013).

Non-users of plant clinics appear to refer to the same type of information sources as the users of plant clinics, except for the use of plant clinics themselves and the fact that they seem to rely more on own experience and neighbours' advice.

\subsection{Indicators of impact}

\subsubsection{Awareness and knowledge}

A pre-requisite for the implementation of a control measure for pest and disease management is the capacity to recognize that the plants present a pest problem. When this happens, a farmer is in the position to detect the presence of a plant pest problem by recognizing one or more signs that the damaged plant displays. This process might not be that straightforward, but if farmers are guided through it, they might be able to recognize it independently and subsequently in the future. We, therefore, measured the capacity of farmers to recognize signs of the presence of a pest such as MSB in their maize plants. We found that although all signs were recognized by both users and non-users of plant clinics but the frequency of recognition by users was greater than non-users, although the difference was not statistically significant (Fig. 2).

\subsubsection{Adoption}

When farmers recognize that their field of maize presents a pest problem, depending on their motivation, availability of and economic access to resources, etc., they are going to act to restore their field. We measured the number and type of practices for pest management that maize farmers implemented. In Fig. 3 we present the frequencies of adoption of practices for MSB management. Although all practices were implemented by both users and non-users, for most practices higher adoption rates were found for users. Some practices, although with low adoption rate, are the prerogative of users, such as trap cropping. The highest rate of adopters was found for application of pesticide, followed by the removal of damaged crop residues, the handpicking of larvae and the monitoring of stem borers. 
Fig. 1 Gender disaggregated sources of information for pest and disease management

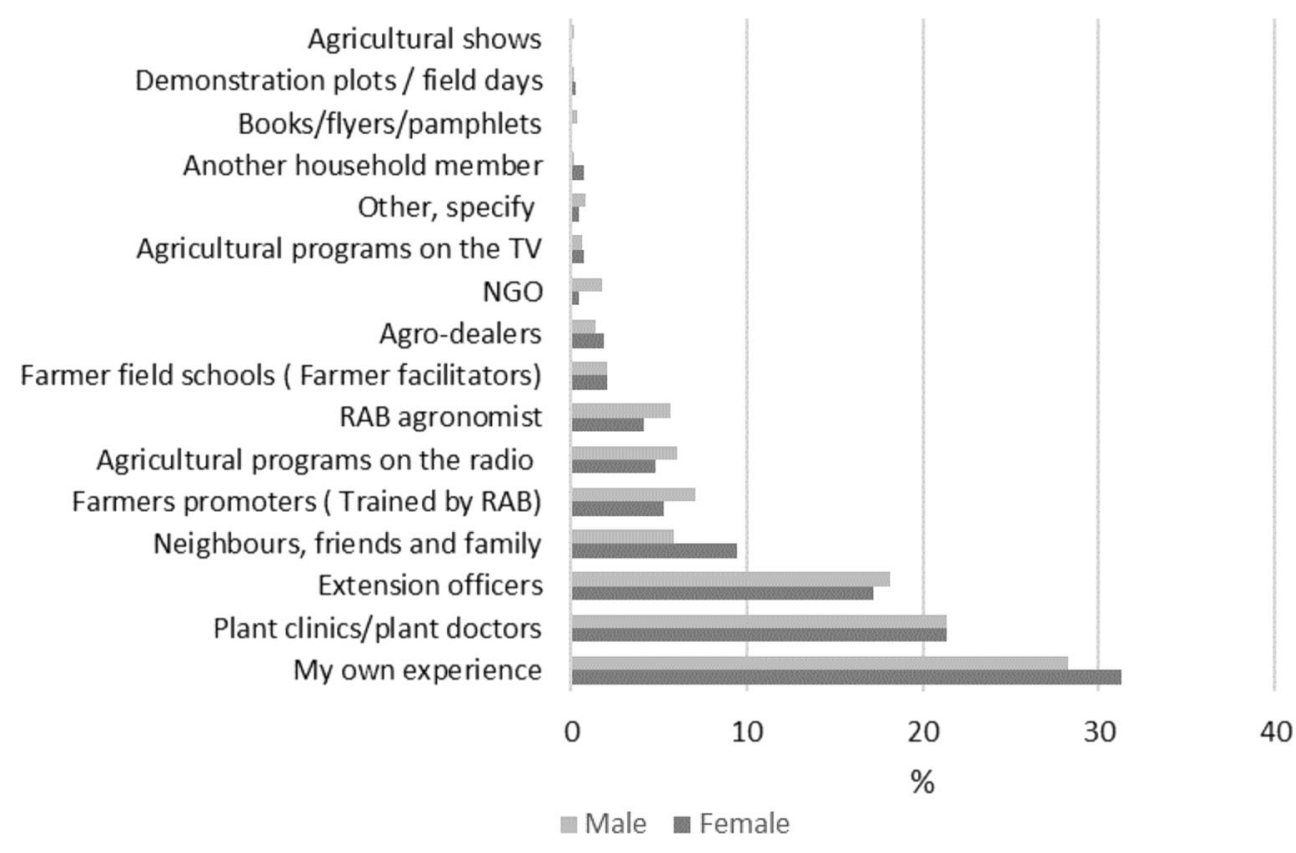

The non-parametric (chi-squared) test shows that significant differences were found for 'application of pesticide' and 'remove crop residues that are damaged', which were more frequently adopted by users. This could be explained by the fact that more users received inputs for free than non-users, in particular fertilizer and pesticide (55 users against 27 non-users). Significantly more non-users than users fed stubble to livestock.
Of the farmers interviewed, $24 \%$ non-users and $11 \%$ users declared they would like to put in place other interventions, in particular 'improving soil fertility' and 'applying pesticides'. Input availability and costs seem to be the major barriers to adoption for 'improving soil fertility' and pesticide use for non-users. The fact that there were more plant clinics users than non-users using pesticide, could suggest that they were
Fig. 2 Frequencies of farmers who recognized specific signs of the presence of MSB

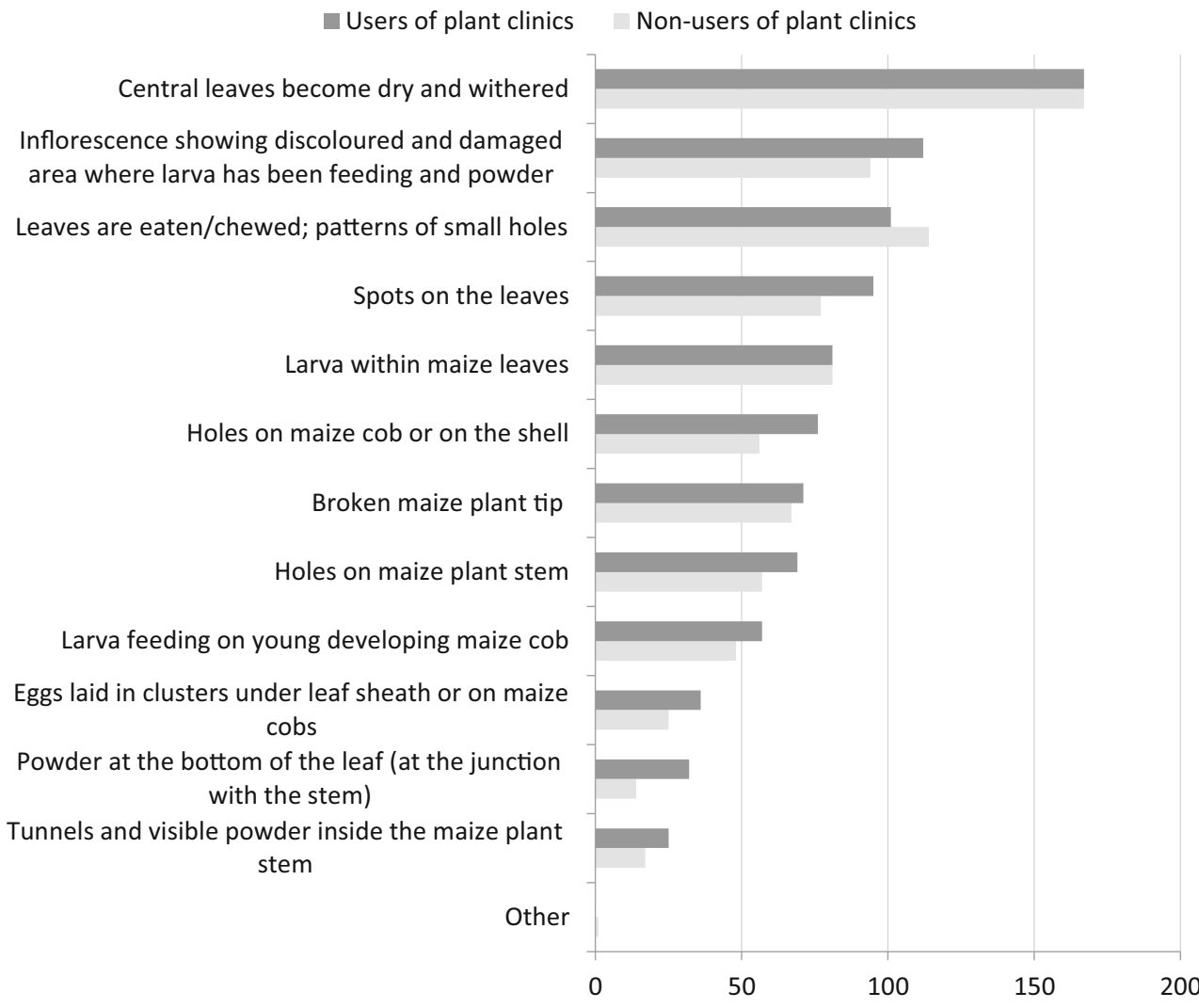



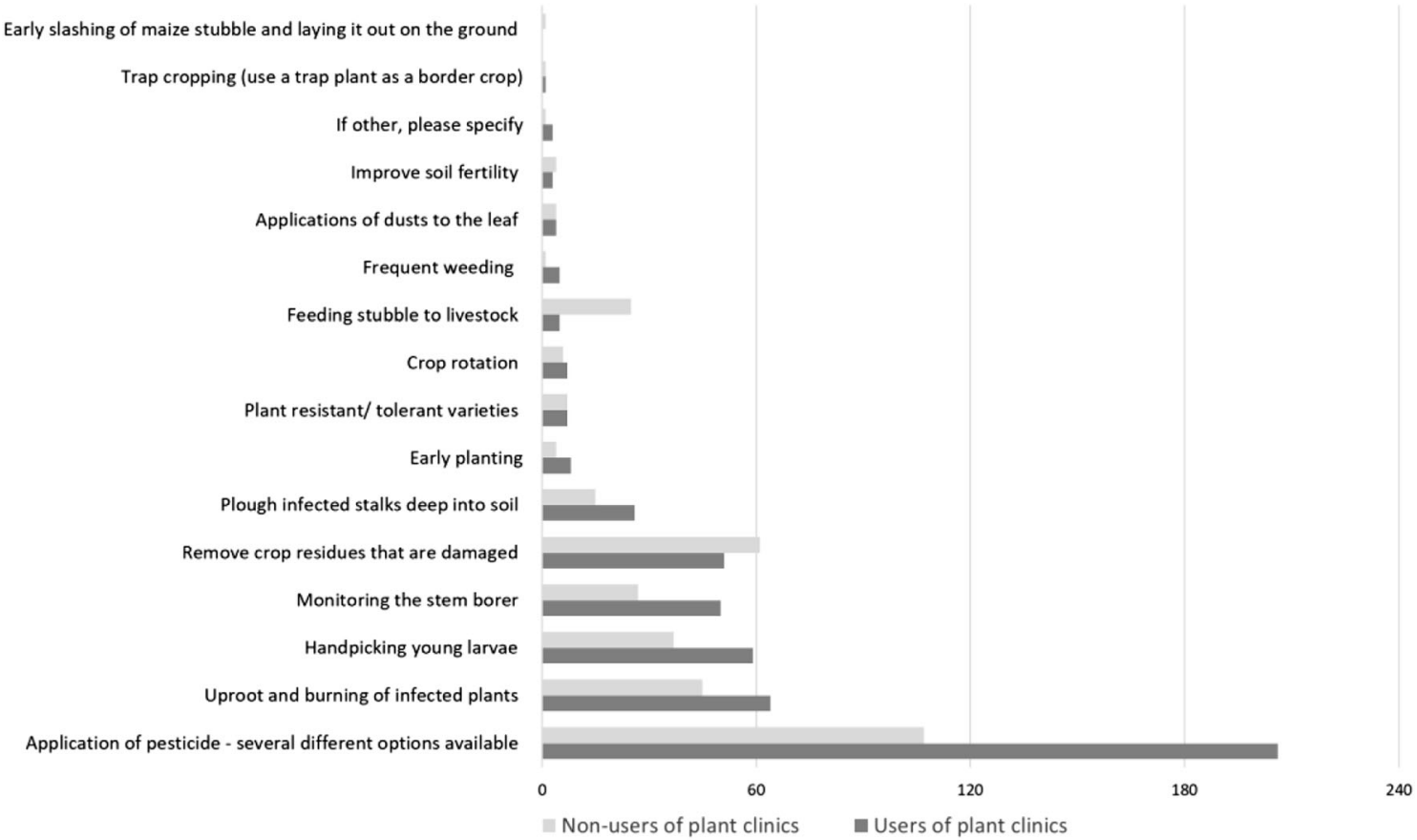

Fig. 3 Frequencies of adopters of practices for management of MSB

better informed about where to obtain inputs and were directed towards purchasing the correct pesticide as well as how to use it. This aspect was also seen in the study of Majuga (2016), who showed that non-users of plant clinics often purchased pesticides without consultation, resulting in purchasing the wrong product. This has cost implications, and can have a series of other implications such as causing pesticide resistance, permanent yield loss and possible repercussion on human health.

Other studies that looked into barriers to input use (Jama and Pizarro 2008; Kelsey 2013; Nicol et al. 2015) showed that barriers to adoption are on both the supply-side (the price, availability, or lack of information about the inputs), and on the demand-side (farmers that do not buy inputs because of lack of credit, labour, sufficient land, or knowledge of technologies, among other possibilities).

In attributing adoption of interventions to a specific source, one has to ensure that farmer adoption took place after the recommendations became available, and verify that the information utilized by farmers originated in the research and extension program (CIMMYT 1993). In this study we asked farmers how they learnt about each intervention they put in place. Table 3 shows sources of information and frequencies of adopters.

Removal of crop residues is a practice, which is mainly based on experience that the farmers have gained over time. Information about uprooting and burning were provided in the majority of cases to adopters through extension officers from the government and plant clinics. Farmers learnt through personal experience and plant clinics the importance of handpicking of larvae and monitoring of stem borer attacks.
In order to compare if the advice coming from plant clinics had changed what the farmers decide to do to address plant pest problems, we asked farmers about practices recently introduced and dropped. We found that only about $12 \%$ of the non-users had introduced new practices, especially application of pesticides and uprooting and burning. However, about $38 \%$ of users had introduced new practices, especially application of pesticides, handpicking of larvae and uprooting and burning. Users attributed the lack of use of these practices in the past mainly due to lack of knowledge and understanding of how to apply the recommendations and the importance of how to apply pesticides. Non-users mainly attributed the lack of use of these practices to the perception that they had a minor plant pest problem.

In terms of practices dropped, only $1 \%$ of the farmers had dropped implementing some practices since 2015.

The government of Rwanda has established an elaborate extension model, called the Twigire Muhinzi. This model runs from the national to the village level where extension staff are deployed. In this extension model, the Rwanda Government has adopted several approaches in order for farmers to access extension services (Kiptot et al. 2013). Considerable attention and priority was also given to the Farmer Field School (FFS) methodology that sees trained farmers become farmer facilitators or farmer promoters (USAID 2011; MINAGRI 2016). $\mathrm{RAB}$ agronomists and extension officers from the government were also very active and conducted training and meetings with farmers, especially at the beginning of the cropping season. Media were also used to disseminate extension technologies through local programmes on television and radio. 
Table 3 Sources of information and frequencies of adopters for MSB management practices. The table shows practices adopted by more than 40 farmers and sources that provided information to more than 5 farmers for at least one practice

\begin{tabular}{|c|c|c|c|c|c|c|c|c|c|c|}
\hline \multirow[b]{3}{*}{ Sources of information } & \multicolumn{10}{|c|}{ Practices for management of MSB } \\
\hline & \multicolumn{2}{|c|}{$\begin{array}{l}\text { Application } \\
\text { of pesticide }\end{array}$} & \multicolumn{2}{|c|}{$\begin{array}{l}\text { Remove crop } \\
\text { residues }\end{array}$} & \multicolumn{2}{|c|}{$\begin{array}{l}\text { Uprooting and } \\
\text { burning }\end{array}$} & \multicolumn{2}{|c|}{$\begin{array}{l}\text { Handpicking } \\
\text { of larvae }\end{array}$} & \multicolumn{2}{|c|}{$\begin{array}{l}\text { Monitoring the } \\
\text { stem borer }\end{array}$} \\
\hline & Users & Non users & Users & Non users & Users & Non users & Users & Non users & Users & Non users \\
\hline My own experience & 31 & 40 & 39 & 57 & 4 & 15 & 9 & 10 & 10 & 13 \\
\hline Neighbours, friends and family & 7 & 15 & 2 & 5 & 2 & 10 & 3 & 8 & 1 & 2 \\
\hline Agricultural programs on the radio & 9 & 7 & - & - & 4 & 7 & - & - & 3 & 2 \\
\hline Extension officers & 64 & 59 & 8 & 6 & 16 & 11 & 25 & 14 & 19 & 6 \\
\hline Agro-dealers /Demo plots/field days & 10 & 9 & - & - & 1 & - & 2 & 2 & 2 & 0 \\
\hline Farmers promoters & 25 & 16 & - & 2 & 10 & 7 & 1 & 0 & 9 & 4 \\
\hline RAB agronomist & 16 & 6 & 1 & - & 3 & 3 & 4 & 1 & 2 & 2 \\
\hline Farmers field schools - farmers facilitators & 11 & 9 & - & 1 & 9 & 6 & - & - & 6 & 6 \\
\hline Plant clinics/plant doctors & 193 & - & 9 & 0 & 50 & - & 37 & 0 & 34 & 0 \\
\hline
\end{tabular}

These contributed to increased information dissemination and chances of adoption among farmers. For those farmers who could access plant clinics, there was an additional chance offered to gather information on pest and disease management, which seems to have boosted the adoption rate in particular for: hand picking of larvae, uprooting and burning, monitoring the stem borer and application of pesticides.

\subsubsection{Factors influencing farmers' adoption}

Table 4 reports the variables that showed significant impact in influencing the uptake of management options. The following variables were not significant and were not included in Table 4: age, household size, household assets, level of education, and net income. In addition, we did not include in the model the following variables: i) maize yields and cost of inputs (because of simultaneous causality); ii) labour surplus, deficiency and balance (because of multicollinearity).

The management option 'biological control' was not included in the model since it was not adopted by any of the survey participants.

We included these information sources in the model: agricultural programmes on TV and radio; own experience (past experience of pest management practices); extension officers; and plant clinics.

The coefficients of the logistic regressions (Table 4) show that information sources seem to have stronger influence on adoption than the other variables. In particular, 'plant clinics' and 'extension officers' are variables associated with the adoption of all or most practices. Social barriers in terms of information sources have been widely described in the literature to be an important cause of failure in the adoption of practices that do not require a substantial financial investment (Adger et al. 2009; De Jalón et al. 2015). Yet, the role that information and knowledge play in the uptake of recommended practices has been highlighted in various studies (Jabbar et al. 2003; Abebe et al. 2013). The positive high association with 'own experience', as per Table 4, suggest that practices are often implemented as the result of self-acquired knowledge, or may indicate increasing confidence generated through personal experience. The study of Jabbar et al. (2003) would support this, showing that farmers move from learning to adoption, and to continuous and discontinuous use over time. The information gathered, the learning and the experience play pivotal roles in the process of adoption.

The high association between adoption and information sources does not necessarily mean that information sources are the most powerful drivers of adoption. Receiving information might not be a sufficient condition for adoption if farmers are unable to access inputs or do not have the funds to purchase them. Consistent with the literature on technology adoption, we also find that farmers with access to credit are more likely to adopt practices that involve liquidity, such as use of inorganic fertilizer and improved seeds (Bryan et al. 2009; FAO 2016). As shown in previous studies (Keya et al. 2017), we also observed a positive impact of free inputs on adoption, in particular of fertilizer and pesticide, which are provided free of charge to farmers by the government and RAB. Furthermore, our data show that the recipients of free inputs are mainly men (two thirds against one third women), which would also explain the positive relationship between gender and prevention/avoidance practices that foresee the use of fertilizer.

Farmers mentioned that the main reasons behind crop failure were drought and insufficient water (mentioned by $55 \%$ of farmers) and pests/diseases (mentioned by $37 \%$ of farmers). Other reasons of crop failure were sickness (2\%) and crops destroyed by livestock/theft (2\%). 
Usually, the most common ex-ante coping strategy for farmers in Africa includes the choice of the crop varieties (e.g. drought tolerant and short term maturing varieties), together with adjustment of cropping patterns and planting dates (Shiferaw et al. 2014). However, our study shows that shocks present a significantly negative effect on adoption of practices such as prevention/avoidance (see Table 4), in particular early planting, or use of resistant/tolerant varieties. These results could be explained by the fact that Rwandan agriculture is mostly rain-fed, and therefore more exposed to weatherrelated risks, especially to severe, frequent, and prolonged dry spells occurring during the cropping seasons; yet, promotion of drought-resistant crop varieties, together with early warning and agro-meteorological information systems with rapid response mechanisms are part of the relatively recent National Adaptation Program of Action (NAPA 2016) that has been tested in a few areas across Rwanda and should be further extended to target larger areas.

A limitation of this analysis is that the potential for adoption of the seven practices was calculated assuming the same weight for all proxies. A further analysis could help to assign different weights to the proxies.

\subsubsection{Assessing potential for adoption}

Figure 4 shows the distribution of the predicted probabilities of adoption of the seven pest management practices.

Considering the median values, the lowest estimated probability of adoption (12\%) is associated with cultural planting/ cropping patterns, while the highest is $89 \%$ and associated with pesticide use. Rational pesticide use is promoted by plant clinics, agro-dealers, who have an interest in promoting pesticide use, and government, who often provides free pesticides. A high probability of adoption is also associated with mechanical interventions in the late crop stage, possibly explained by the fact that these practices do not have an associated cost. The rest of the practices analysed present probabilities of adoption that are far below $40 \%$. Some of these practices present an elevated cost for the household, such as for example planting resistant/tolerant varieties. Seeds are also provided for free but in low quantity ( $16 \%$ of farmers received seeds compared with $66 \%$ of farmers who received pesticide). Other practices require a certain degree of knowledge/training before being implemented, such as for example planting/ cropping patterns, prevention/avoidance and mechanical early stage interventions.

\subsubsection{Production}

We found the average production of maize across Rwanda (Fig. 5) was $1.7 \mathrm{t} / \mathrm{ha}$, with a maximum value of $4.0 \mathrm{t} / \mathrm{ha}$ and a minimum value of $0.3 \mathrm{t} / \mathrm{ha}$. Such variability in yields has also been recorded in other studies (Kiptot et al. 2013; NIRS 


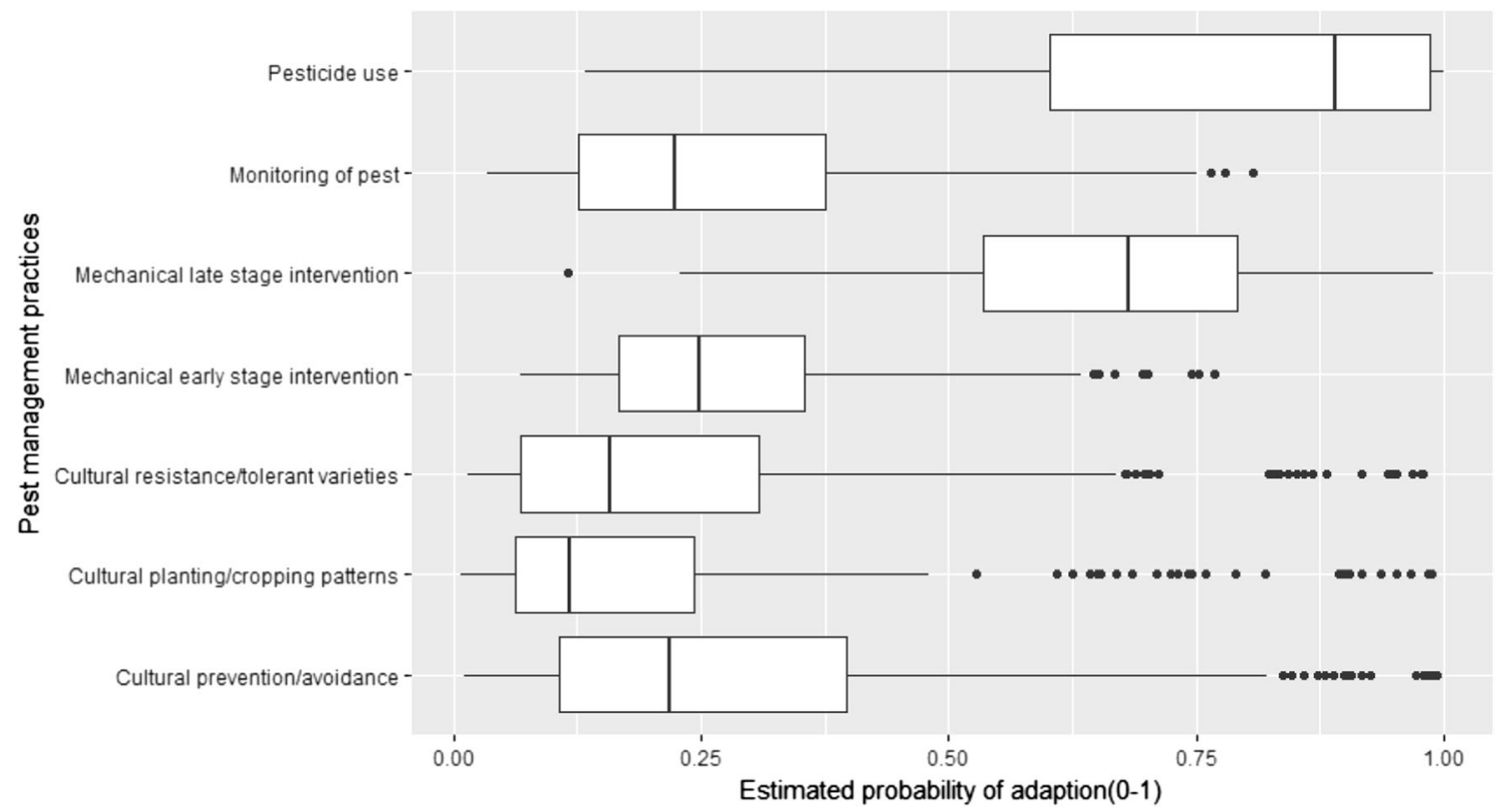

Fig. 4 Estimated probability of adoption of pest management practices for MSB. The middle vertical lines within each box indicate the median, boxes extend from the 25 th to the 75 th percentile, and horizontal lines (whiskers) extend from the 10th to 90th percentile of estimations. Dots are outliers

2017). The AEZ that showed the highest production is the Central plateau, with an average production of $1.8 \mathrm{t} / \mathrm{ha}$, whilst the one with lowest production was the Congo Nile watershed divide, with 1.4 tha. The comparisons of maize yield for users and non-users of plant clinics revealed that users on average have higher yields (Fig. 5). This difference is highly significant $(P<0.001)$. In terms of differences across the AEZ, yields of users are higher than yields of non-users across all AEZs except for the Burebuka highlands. However, the difference between yields of users and non-users is highly significant only for Central plateau and Congo Nile watershed divide.

Analysis was also conducted to assess differences between yield of maize for men- and women-led households. Although men-led households on average have slightly higher production $(1661 \mathrm{~kg} / \mathrm{ha})$ than women-led households $(1658 \mathrm{~kg} / \mathrm{ha})$, this difference is not statistically significant. Despite maize being in general managed by women across the country, they

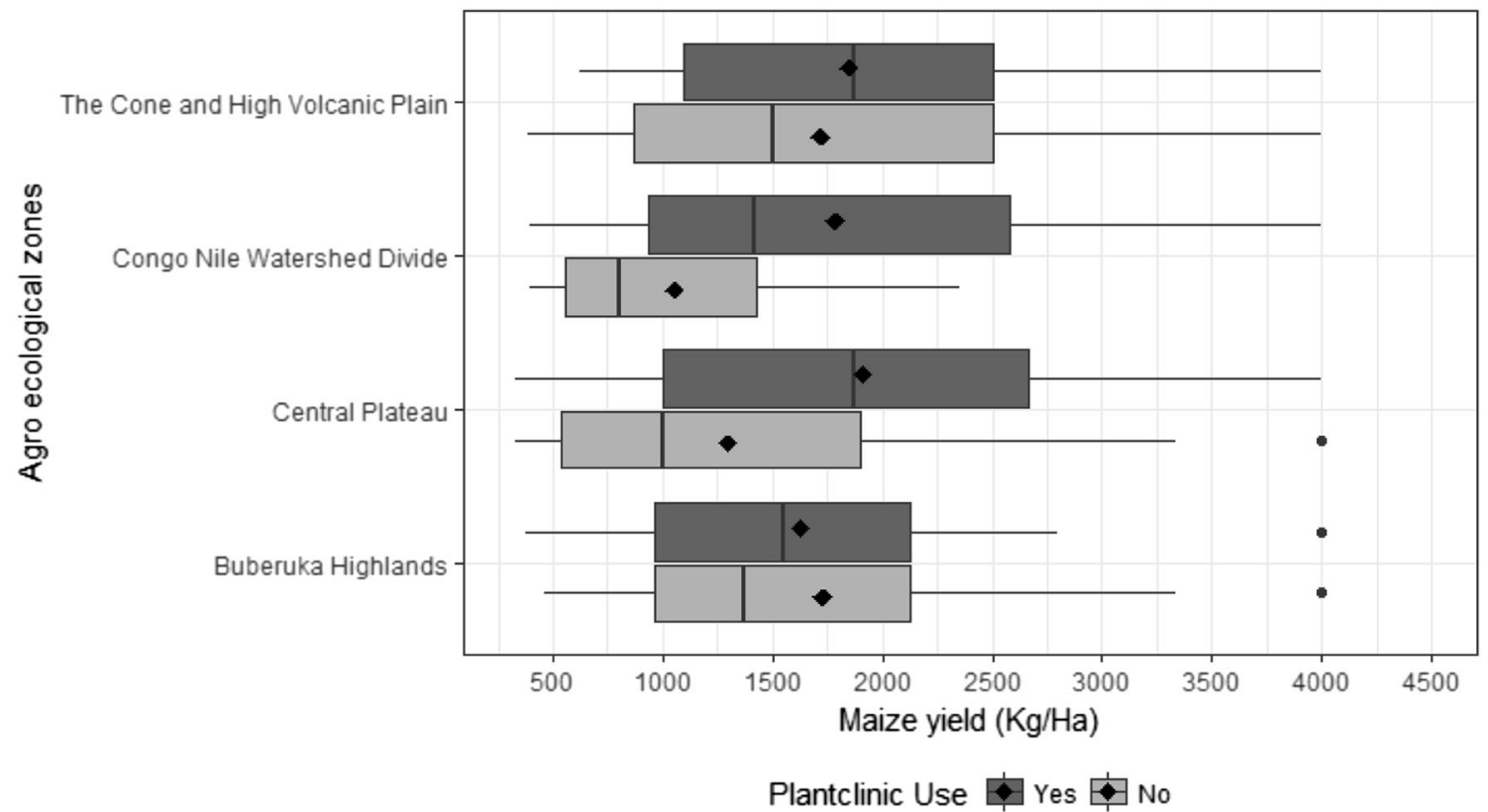

Fig. 5 Yield of maize ( $\mathrm{kg} / \mathrm{ha})$ across the four different AEZ. The middle vertical lines within each box indicate the median and the black diamonds indicate the means. Boxes extend from the 25 th to the 75 th percentile, and horizontal lines (whiskers) extend from the 10th to 90th percentile of estimations. Dots are outliers 
Table 5 Determinants of yields (correspondent regressions coefficients)

\begin{tabular}{lcc}
\hline Variables & Coefficient & $p$ value \\
\hline Gender & 0.776 & 0.438 \\
Age & -0.289 & 0.773 \\
Household size & -0.278 & 0.781 \\
Maize land & -2.038 & $\mathbf{0 . 0 4 2} *$ \\
Cost of inputs & 6.562 & $\mathbf{0 . 0 0 0} * * *$ \\
Credit source & 2.203 & $\mathbf{0 . 0 2 8} *$ \\
Education & 1.696 & $\mathbf{0 . 0 9 1}$ \\
Inputs received & -0.652 & 0.515 \\
Shocks & -2.456 & $\mathbf{0 . 0 1 4}$ \\
Own experience & 1.751 & $\mathbf{0 . 0 8 1}$ \\
Radio and TV & -1.721 & $\mathbf{0 . 0 8 6}$ \\
Extension & -0.595 & 0.552 \\
Plant clinics & 1.369 & 0.172 \\
\hline
\end{tabular}

$* * * p<0.00 ; * * p<0.01 ; * p<0.05 ; . p<0.1$

experience limited access to government initiatives in Rwanda, such as the Crop Intensification Program (CIP), because the inputs (chemicals, fertilizers, seeds) are too expensive and many of the technologies are labour intensive, restricting women's participation (World Bank 2015).

To further assess variables that influence yields we ran a multiple linear regression (Table 5). The regression shows that variables that have a positive and significant relationship with yields are inputs costs and access to credit. The variables that have a negative relationship with yield are shocks, and land size. The latter finding conforms to the global literature

Table 6 Summary of main statistics for users and non-users of plant clinics (mean and t-test)

\begin{tabular}{llll}
\hline Variables & Users & Non-users & T-test \\
\hline Age & 46.6 & 46.5 & 0.904 \\
Education highest level for respondent & 1.4 & 1.5 & $0.273^{+}$ \\
Household size & 5.1 & 5.1 & $0.788^{+}$ \\
Land per capita (ha) & 0.097 & 0.079 & $0.012^{* *}$ \\
Yield (kg/ha) & 1854.9 & 1458.7 & $0.000^{* * *}$ \\
Labour surplus, deficiency, balance & 0.09 & 0.08 & $0.009^{* * *}$ \\
Asset & 34.7 & 34.6 & 0.792 \\
Pesticide cost per ha (USD) & 12.3 & 6.0 & $0.000^{* * *}$ \\
Seeds cost per ha (USD) & 4.5 & 5.1 & $0.066^{*}$ \\
Fertilizer cost per ha USD & 35.5 & 27.1 & $0.001^{* * *}$ \\
Total costs per ha (USD) & 77.2 & 67.5 & $0.047^{* *}$ \\
Total costs per tonnes (USD) & 46.2 & 52.5 & $0.084^{*}$ \\
Net income per ha (USD) & 348.2 & 268.9 & $0.000^{* * *}$ \\
\hline
\end{tabular}

${ }^{+}$these are discrete variables, therefore we used the non parametric Wilcoxon rank sum test with continuity correction to assess whether users and non-users differences are statistically significant

$* p<1 ; * * p<.05 ; * * * p<.01$
(Eastwood et al. 2010; Lipton 2011), and specifically to a study about Rwanda (Ali and Deininger 2014). Labour market imperfections seem to be a key reason for the inverse farmsize productivity relationship.

Overall, users of clinics have a higher net income per ha than non-users (348.2 USD/ha vs $268.9 \mathrm{USD} / \mathrm{ha}$ ) and this difference is highly significant. This reflects the higher yields, despite higher average costs per ha for users (77.2 USD/ha) than non-users (67.5 USD/ha; Table 6).

Our calculation of total costs includes: improved seeds, fertilizers, and pesticides. Whilst the survey also collected information on herbicide costs, none of the farmers declared expenditure for this input. This is in line with the Rwandan national policy, which does not support the use of herbicides (Kabigiri et al. 2015; REMA 2011). However, it is also possible that farmers combine herbicides with other pesticides. We found high man-hour variability among farmers, and, therefore, could not include this variable among the costs.

\section{Conclusions}

Our results suggest that plant clinics can boost the awareness and knowledge of signs of pests, and also facilitate adoption of integrated pest management practices. This in turn would lead to higher yields for plant clinic users. Higher yields are also accompanied by greater use of complementary inputs, which increase production costs. However, the net income for users is greater despite higher costs per ha.

Extension officers from the government play an important role in Rwanda among the information sources contributing to pest management practice adoption. The country benefits from a solid extension service, which, combined with the service rendered by plant clinics, enhance the probability of adoption further.

Nonetheless, we found evidence that targeting male and female farmers equally in terms of both provision of information and free inputs, could improve adoption rates for female farmers. A gender asymmetry in information is also found with respect to provision of free inputs, with initiatives that still target males. "Anti-women biases" by public and private agencies still prevail, which pose a real challenge to overcome.

The practices associated with the highest likelihood of adoption are pesticide use and mechanical interventions at late crop stage. Further efforts should be made to promote those options for pest management that currently have lower adoption probabilities, such as resistance/tolerant varieties, planting/cropping patterns, prevention/avoidance and mechanical early stage interventions. The least adopted pest management practices are in general associated with technical challenges - e.g., lack of knowledge of technology implementation - and financial constraints. The latter 
especially concerns the cultivation of resistant/tolerant maize varieties. The government of Rwanda has developed an integrated pest management framework, which emphasises the use of resistant varieties. Under the Crop Intensification Program (CIP) initiated in 2007 by the Ministry of Agriculture and Animal Resources (MINAGRI), seeds of some priority crops such as maize were imported and distributed freely to farmers. Despite this, there seems to be room for improvement regarding the distribution of seeds of resistant varieties to more farmers.

Additional policy implications are that there is a need for a coordinated effort from the government to increase the economic support toward the promotion of more expensive practices, and enhancing training for those practices that require extra knowledge. Countries that significantly increase their investment in agricultural research, extension and farmers' schooling achieve faster rates of adoption of a wide range of technologies (Mundlak 2000; Cervantes-Godoy and Dewbre 2010). Policy makers would be interested in the most effective ways to improve adoption at minimal cost. Therefore, this kind of research could be integrated and further developed with an analysis of those options that would enhance cost-effective patterns of adoption.

Adoption of pest management practices can be fostered in a number of ways and this study shows that plant clinics and extension are excellent ways of doing so. However, improvements in extension services, both in terms of coverage and efficiency, would be necessary to help farmers overcome barriers to information and adoption.

\footnotetext{
Acknowledgements $\mathrm{CABI}$ is an international intergovernmental organisation and we gratefully acknowledge the core financial support from our member countries (and lead agencies) including the United Kingdom (Department for International Development (DFID)), China (Chinese Ministry of Agriculture), Australia (Australian Centre for International Agricultural Research), Canada (Agriculture and Agri-Food Canada), Netherlands (Directorate-General for International Cooperation), and Switzerland (Swiss Agency for Development and Cooperation). The views expressed in this document are those of the authors and do not necessarily reflect the views of DFID. We thank Abdillahi Alawy, Dannie Romney and the Associate Editor for the useful comments on an earlier version of this manuscript. We warmly thank the 10 enumerators who conducted the household survey and the 644 survey participants for their time and responses.
}

\section{Compliance with ethical standards}

Ethical approval All procedures performed in studies involving human participants were in accordance with the ethical standards of the institutional and/or national research committee and with the 1964 Helsinki declaration and its later amendments or comparable ethical standards.

Conflict of interest The authors declare that they have no conflict of interest.
Informed consent Informed consent was obtained from all individual participants included in the study.

Open Access This article is distributed under the terms of the Creative Commons Attribution 4.0 International License (http:// creativecommons.org/licenses/by/4.0/), which permits unrestricted use, distribution, and reproduction in any medium, provided you give appropriate credit to the original author(s) and the source, provide a link to the Creative Commons license, and indicate if changes were made.

\section{References}

Abebe, G. K., Bijmana, J., Pascucci, S., \& Omta, O. (2013). Adoption of improved potato varieties in Ethiopia: the role of agricultural knowledge and innovation system and smallholder farmers' quality assessment. Agricultural Systems, 122, 22-32. https://doi.org/10.1016/j. agsy.2013.07.008.

Adelson, J. L. (2013). Educational research with real data: reducing selection bias with propensity score analysis. Practical Assessment Research and Evaluation, 18(15), 2.

Adger, W. N., Dessai, S., Goulden, M., Hulme, M., Lorenzoni, I., Nelson, D. R., Naess, L. O., Wolf, J., \& Wreford, A. (2009). Are there social limits to adaptation to climate change? Climatic Change, 93, 335354. https://doi.org/10.1007/s10584-008-9520-z.

Ali, D. A., \& Deininger, K. (2014). Is there a farm size-productivity relationship in African agriculture? Evidence from Rwanda. Land Economics, 91(2), 317-343.

American Institutes for Research. (2015). Evaluation of PlantwiseKenya: Baseline report. Washington, DC, 138 pp.

Bentley, J. W., Boa, E., Danielsen, S., \& Zakaria, A. K. M. (2007). Plant clinics for healthy crops. Leisa Magazine, 23(4), 16-17.

Bentley, J. W., Boa, E., Danielsen, S., Franco, P., Antezana, O., Villarroel, B., \& Rodríguez, H. (2009). Plant health clinics in Bolivia 2000-2009: operations and preliminary results. Food Security, 1(3), 371-386.

Bentley, J. W., Danielsen, S., Phiri, N., Yakosa, C. T., Nylungwe, N., Neves, E., Hidalgo, E., Sharma, A., Pandit, V., \& Sharma, D. R. (2018). Farmer responses to technical advice offered at plant clinics in Malawi, Costa Rica and Nepal. International Journal of Agricultural Sustainability, 16(2), 187-200. https://doi.org/10. 1080/14735903.2018.1440473.

Boa, E. (2010). Plant Healthcare for poor farmers around the world: Gathering demand and innovative responses. In N. Hardwick \& M. Lodovica Gullino (Eds.), Knwoledge and technology transfer for plant pathology (pp. 1-16, Vol. 4). Dordrecht, Heidelberg, London, New York: Springer.

Boa, E., Franco, J., Chaudhury, M., Simbalaya, P., Van Der Linde, E. (2016). Plant Health Clinics. Note 23. GFRAS good practice notes for extension and advisory services. GFRAS, Lausanne, Switzerland.

Brubaker, J., Danielsen S., Oluput M., Romney D., \& Ochatum N. (2013). Impact evaluation of plant clinics: Teso, Uganda. CABI Working Paper 6, 88 pp. Retrieved online on 02 December 2018.

Bryan, E., Deressa, T. T., Gbetibuo, G. A., \& Ringler, C. (2009). Adaptation to climate change in Ethiopia and South Africa: options and constraints. Environmental Science and Policy, 12(4), 413-426.

Bryan, E., Ringler, C., Okoba, B., Roncoli, C., Silvestri, S., \& Herrero, M. (2013). Adapting agriculture to climate change in Kenya: household strategies and determinants. Journal of Environmental Management, 114, 26-35. https://doi.org/10.1016/j.jenvman.2012.10.036.

Cervantes-Godoy, D., \& Dewbre, J. (2010). Economic importance of agriculture for poverty reduction, OECD, food, agriculture and fisheries working papers, no. 23, OECD Publishing, 26 pp. https://doi. org/10.1787/5kmmv9s20944-en. 
CIMMYT Economics Program. (1993). The adoption of agricultural technology: a guide for survey design. Mexico, D.F.: CIMMYT, 98pp. Retrieved online on 02 December 2018.

Danielsen, S., \& Kelly, P. (2010). A novel approach to quality assessment of plant health clinics. International Journal of Agricultural Sustainability, 8, 257-269.

Danielsen, S., \& Matsiko, F. B. (2016). Using a plant health system framework to assess plant clinics performance in Uganda. Food Security, 8(2), 345-359.

Danielsen, S., Centeno, J., López, J., Lezama, L., Varela, G., Castillo, P., Narváez, C., Zeledón, I., Pavón, F., \& Boa, E. (2011). Innovations in plant health services in Nicaragua: from grassroots experiment to a systems approach. Journal of International Development, 25(7), 968-986. https://doi.org/10.1002/jid.1786.

De Jalón, S. G., Silvestri, S., Granados, A., \& Iglesias, A. (2015). Behavioural barriers in response to climate change in agricultural communities: an example from Kenya. Regional Environmental Change, 15(5), 851865. https://doi.org/10.1007/s10113-014-0676-y.

Eastwood, R., Lipton, M., \& Newell, A. (2010). Farm size. In P. L. Pingali \& R. E. Evenson (Eds.), Handbook of agricultural economics (912 pp). Elsevier: North Holland.

Ehler, L. E. (2006). Integrated pest management (IPM): Definition, historical development and implementation, and the other IPM. Pest Management Science, 62 (9), 787-789. https://doi.org/10.1002/ps. 1247.

Evenson, R. (1996). The economic contributions of agricultural extension to agricultural and rural development. In B. E. Swanson, R. P. Bentze, \& A. J. Sofranko (Eds.), Improving agricultural extension: A reference manual (303 pp). Food and Agriculture Organization of the United Nations: Rome.

FAO. (2016). Smallholder productivity under climatic variability: Adoption and impact of widely promoted agricultural practices in Tanzania, by Aslihan Arslan, Federico Belotti and Leslie Lipper. ESA Working Paper No. 16-03, pp 76. Rome: FAO.

Geddes, A.M.W. (1990). The relative importance of crop pests in subSaharan Africa. NRI Bulletin, 36, 76.

Hartung, C., Anokwa, Y., Brunette, W., Lerer, A., Tseng, C. \& Borriello, G. (2010). Open data kit: Tools to build information services for developing regions. ICTD '10 Proceedings of the 4th ACM/IEEE International Conference on Information and Communication Technologies and Development. 18. London, United Kingdom December 13 - 16, 2010

Hatfield, J.L., \& Karlen, D.L. (eds) (1994). Sustainable agriculture systems (pp. 316). Boca Raton: Lewis Publishers

Ho, D., Kosuke, I., King, G., \& Stuart, E. (2011). MatchIt: Nonparametric preprocessing for parametric causal inference. 42(8), 1-28.

ILO. (2004). Investing in every child: An economic study of the costs and benefits of eliminating child labour (pp. 4-5). Geneva: IPEC.

Jabbar, M. A., Mohamed Saleem, M. A., Gebreselassie, S., \& Beyene, H. (2003). Role of knowledge in the adoption of new agricultural technologies: an approach and an application. International Journal of Agricultural Resources, Governance and Ecology, 2(3/4), 312-327.

Jama, B., \& Pizarro, G. (2008). Agriculture in Africa: strategies to improve and sustain smallholder production systems. Annals of the New York Academy of Sciences, 1136, 218-232. https://doi.org/10. 1196/annals.1425.034.

Kabigiri, M., Musana, B., Ngetich, F., Mugwe, J., Mukuralinda, A., \& Nabahungu, N. L. (2015). Applicability of conservation agriculture for climate change adaptation in Rwanda's situation. Journal of Soil Science and Environmental Management, 6(9), 241-224.

Kabubo-Mariara, J. (2008). Climate change adaptation and livestock activity choices in Kenya: an economic analysis. Natural Resources Forum, (32), 131-141.

Kelsey, J.B. (2013). Constraints on the adoption of agricultural technologies in developing countries. Literature review, agricultural technology adoption initiative, J-PAL (MIT) and CEGA (UC Berkeley), 70 pp.
Keya, M., Onyango, A. C., \& Obara, J. (2017). The effect of free farm input supply on agricultural technology adoption among small scale maize farmers in Matungu sub-county, Kakamega county. International Journal of Advance Research, 5(5), 423-431.

Kiptot, E., Kinutia, R., \& Mutaganda, A. (2013). The extension system in Rwanda: a focus on Bugesera, Rubavu and Nyabihu districts. ACIAR trees for food security project, $80 \mathrm{pp}$. World Agroforestry Centre (ICRAF), Rwanda Agricultural Board (RAB).

Kristjanson, P., Bryan, E., Bernier, Q., Twyman, J., Meinzen-Dick, R., Kiera, C., Ringler, C., Jost, C., \& Doss, C. (2017). Addressing gender in agricultural research for development in the face of a changing climate: where are we and where should we be going? International Journal of Agricultural Sustainability, 15(5), 482-500. https://doi. org/10.1080/14735903.2017.1336411.

Lipton, M. (2011). Land reform in developing countries: property rights and property wrongs. Asian-Pacific Economic Literature, 25(1), 170-170. https://doi.org/10.1111/j.1467-8411.2011.01287.x.

Macauley, H., \& Ramadjita, T. (2015). Cereal crops: Rice, maize, millet, sorghum, wheat: Background paper for conference on 'feeding Africa: An action plan for African Agricultural Transformation', 21-23 October, Dakar, Senegal, United Nations Commission for Africa and ICRISAT, $36 \mathrm{pp}$.

Majuga, J.N. (2016). Exploring the functioning of plant clinics in Rwanda: Clinic operation and farmer attendance. Plantwise internship report, $38 \mathrm{pp}$.

Majuga, J. C., Uzayisenga, B., Kalisa, J. P., Almekinders, C., \& Danielsen, S. (2018). "Here we give advice for free": the functioning of plant clinics in Rwanda. Development in Practice, 28(7), 858-871. https://doi.org/10.1080/09614524.2018.1492515.

Ministry of Agriculture and Animal Resources of the Republic of Rwanda (MINAGRI) \& The Belgian Development Agency. (2016). Twigire Muhinzi Reflection Paper, 16 pp.

Mundlak, Y. (2000). Agriculture and economic growth: Theory and measurement (pp. 479). Massachusetts: Harvard University Press.

NAPA (2016). National adaptation programmes of action to climate change - Rwanda, 85 pp.

National Institute of Statistics of Rwanda (NISR). (2017). Seasonal Agricultural Survey (SAS) 2017. Retrieved online on 02 December 2018.

Netherlands Ministerie van Landbouw en Visserij and Euroconsult. (1989). Agricultural compendium for rural development in the tropics and subtropics (3rd ed.740 pp). Amsterdam: Elsevier.

Nicol, A., Langan, S., Victor, M., \& Gonsalves, J. (Eds.) (2015). Watersmart agriculture in East Africa. Colombo, Sri Lanka: International Water Management Institute (IWMI). CGIAR Research Program on Water, Land and Ecosystems (WLE); Kampala, Uganda: Global Water Initiative East Africa (GWI EA). 352 pp. https://doi.org/10. 5337/2015.203.

Nsabimana J., Uzayisenga B., \& Kalisa J.P. (2015). Learning from plant health clinics in Rwanda. Platwise internship report, $68 \mathrm{pp}$.

Perez, C., Jones, E., Kristjanson, P., Cramer, L., Thornton, P., Förch, W., \& Barahona, C. (2014). How resilient are farming households, communities, men and women to a changing climate in Africa? CCAFS Working Paper no. 80, 34 pp. Retrieved online on 02 December 2018.

R Core Team. (2016). R: A language and environment for statistical computing. R Foundation for Statistical Computing, Vienna, Austria. Retrieved from http://www.R-project.org/. Accessed 2 Dec 2018.

Rajendran, G., \& Islam, R. (2017). Plant clinics in Bangladesh: Are farmers losing less and feeding more? CABI case study 19, $11 \mathrm{pp}$. https://doi.org/10.1079/CABICOMM-25-8072. Retrieved online on 02 December 2018.

REMA. (2011). The national integrated pest management (IPM) framework for Rwanda. 112 pp. Retrieved online on 02 December 2018.

Rosenbaum, P. R., \& Rubin, D. (1983). The central role of the propensity score in observational studies for causal effects. Biometrika, 70(1), 41-55. 
Rudner, L. M. \& Peyton, J. (2006). Consider propensity scores to compare treatments. Practical Assessment Research \& Evaluation, 11(9), 1-19.

Rweyemamu M., Otim-Nape W., \& Serwadda D (2006). Foresight. Infectious diseases: preparing for the future, Africa Office of Science and innovation, London, p. 1-120. http://www.bis.gov.uk/ assets/bispartners/foresight/docs/infectious-diseases/a1_id_africa. pdf. Accessed Nov 2018.

Schreiner, M. (2016). Simple poverty scorecard, 167 pp. http://www. simplepovertyscorecard.com/RWA_2010_ENG.pdf. Retrieved online on 02 December 2018.

Shiferaw, B., Tesfaye, K., Kassie, M., Abate, T., Prasanna, B. M., \& Menkir, A. (2014). Managing vulnerability to drought and enhancing livelihood resilience in sub-Saharan Africa: technological, institutional and policy options. Weather and Climate Extremes, 3, 6769.

Srivastava, M. P. (2013). Plant clinic towards plant health and food security. ESci Journal of Plant Pathology, 2(3), 193-203.

Staal, S.J., Balttenweck, I., Waithaka, M.M., Wolff, T.D. Njoroge, L. (2002). Location and uptake: integrated household and GIS analysis of technology adoption and land use, with application to smallholder dairy farms in Kenya. Agricultural Economics, 27, 295-315.

Stone, C.A., \& Tang, Y. (2013). Comparing propensity score methods in balancing covariates and recovering impact in small sample educational program evaluations. Practical Assessment, Research \& Evaluation, 18(13). Available online: http://pareonline.net/getvn. asp? $=18 \& n=13$. Retrieved online 2 December 2018.

Stuart, E. A. (2010). Matching methods for causal inference: a review and a look forward. Statistical Science, 25(1), 1-21.

Thornton, P. K., Jones, P. G., Owiyo, T., Kruska, R. L., Herrero, M., Orindi, V., Bhadwal, S., Kristjanson, P., Notenbaert, A., Bekele, N., \& Omolo, A. (2008). Climate change and poverty in Africa: mapping hotspots of vulnerability. African Journal of Agricultural Resources Economics, 2(1), 24-44.

Thornton, P. K., Jones, P. G., Alagarswamy, G., Andresen, J., \& Herrero, M. (2010). Adapting to climate change: agricultural system and household impacts in East Africa. Agricultural Systems, 103, 73-82.

USAID. (2011). Comprehensive assessment of extension services in Rwanda, $121 \mathrm{pp}$. https:/www.agrilinks.org/sites/default/ files/resource/files/MEAS\%20 Country\%20Report\% 20RWANDA\%20-\%20May\%202011.pdf. Retrieved online on 02 December 2018.

Wanda, K., Ferris, R.S.B., Rucibango, M., Tuyisenge, J., Munkankubana, D., Kagiraneza, B., Ngaboyisonga, C., Gatarayiha, C., Uwantege, C., Kanyange, C., \& Butare, L. (2002). Maize sub-sector market survey, Rwanda. CIAT-ATDT/ISAR/IITA-FOODNET and PEARL Project - Rwanda, 84 pp. https://betuco.be/rwanda/Maize\%20subsector\%20market\%20survey\%20Rwanda.pdf. Retrieved online on 02 December 2018.

World Bank. (2015). Rwanda: Agricultural sector risk assessment, World Bank Group report 96290-RW. Washington, D.C.: World Bank Group, prepared by Giertz, A., Mudahar, M., Gray, G., Rubaiza, R., Galperin, D., \& Suit, K. http://documents.worldbank.org/ curated/en/525111468180254519/pdf/96290-WPP148140Box393232B-PUBLIC-TAP-Rwanda-ASRA-WEB-10062015.pdf. Retrieved online on 02 December 2018.

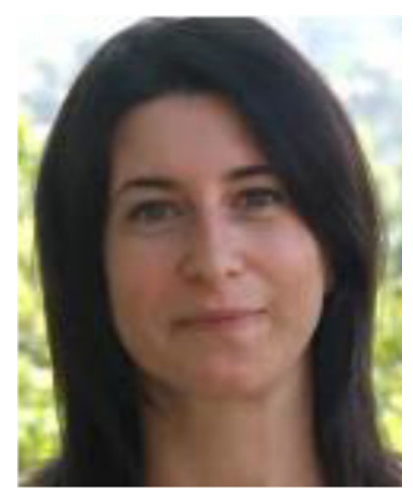

Dr. Silvia Silvestri is senior Socio-Economist at the Centre for Agriculture and Biosciences International (CABI). She joined CABI in 2016 to lead social science research and support the design and implementation of programs components, as well as advising on socio-economics elements across the organization. Before joining CABI Silvia worked as a senior scientist for environment and livelihoods for the Consultative Group for International Agricultural Research (CGIAR) and as programme officer for the United Nation Environment Program-World Conservation Monitoring Center (UNEPWCMC). Over the last 16 years she has been working on various facets of research: academic research, bridging research and policy, research for development and action research. She has published on agriculture, climate change, food security and gender. In this framework she has been involved with a number of major international development initiatives with a focus on poverty alleviation.

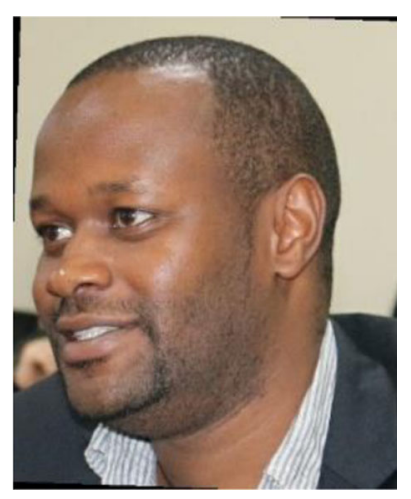

Martin Macharia is Statistical analyst at GreenLight Planet, Inc. where he develops predictive models and advanced analytics for ongoing efficiency and stability. Prior to this appointment he was data manager at $\mathrm{CAB}$ International and data management consultant at the International Center for Tropical Agriculture (CIAT).

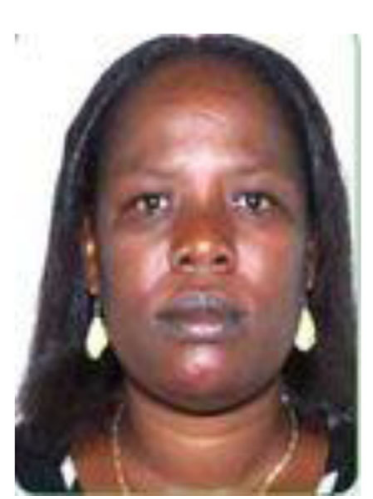

Bellancile Uzayisenga is Head of the Crop Protection Programme for the Rwandan Agricultural Board (RAB). She coordinates plant protection programmes and in addition she is the national coordinator for the Plantwise programme that focuses on pest and disease management worldwide. 